Ju rnal Instruksional, Volume 1, Nomor 2, April 2020111

ISSN: 2686-5645

\title{
PENGEMBANGAN STANDAR DESAIN LAYANAN CLOUD BERDASARKAN ISO/IEC 20000: STUDI KASUS PT. XYZ
}

\author{
${ }^{1}$ Ahmad Fikri Adriansyah, ${ }^{2}$ Bob Hardian, ${ }^{3}$ Gladhi Guarddin \\ ${ }^{1}$ Pendidikan Teknologi Informasi, Universitas Muhammadiyah Jakarta \\ email: fikri.adriansyah@gmail.com \\ ${ }^{2}$ Magister Teknologi Informasi, Universitas Indonesia \\ email: hardian@cs.ui.ac.id \\ ${ }^{2}$ Magister Teknologi Informasi, Universitas Indonesia \\ email: adin@ ui.ac.id
}

\begin{abstract}
PT XYZ is now transforming its business from traditional telecommunication provider to an ICT (Information \& Communication Technology) provider in order to deal with current stringent business competition. One of its strategic initiatives is to improve Cloud service market penetration based on the fact from market size analysis result which has reported that Cloud service would appear as an IT service with highest growth throughout Asia Pacific region from 2013 to 2018 (i.e., 49\%). However, PT XYZ has reported its Cloud service sales only achieved 52\% of its total revenue target in 2014 fiscal year. One of the root causes found is the lack of standard in performing design on Cloud service. As ISO/IEC 20000 certification holder, PT XYZ has to improve its IT service management practices continuously including its service design stage. This research goal is to build design standard on Cloud service in PT XYZ using two internationally recognized Information Technology Service Management (ITSM) frameworks, i.e. Information Technology Infrastructure Library (ITIL) version 3 and Microsoft Operation Framework (MOF) version 4, as well as Cloud Computing Reference Architecture (CCRA) and guidance on the application of ISO/IEC 20000-1 to Cloud Services (ISO/IEC TR 20000-9:2015). As the result, a design process flow and design documentation templates are proposed to be used as Cloud service design standard in PT XYZ.
\end{abstract}

Keywords: Cloud Service, Cloud Computing Reference Architecture; Information Technology Infrastructure Library; Information Technology Service Management; ISO/IEC 20000

\begin{abstract}
Abstrak
PT XYZ menghadapi persaingan bisnis teknologi informasi (TI) dan komunikasi dengan melakukan transformasi bisnis dari penyedia layanan telekomunikasi tradisional menjadi penyedia solusi ICT (Information Communication Technology). PT XYZ mencanangkan peningkatan penetrasi pasar layanan Cloud sebagai inisiatif strategis berdasarkan analisis ukuran pasar ICT selama periode tahun 2013 sampai dengan tahun 2018 yang menyatakan bahwa layanan Cloud diprediksikan akan menjadi layanan TI dengan pertumbuhan tertinggi di regional asia-pasifik, yaitu sebesar $49 \%$. Namun, fakta menunjukkan bahwa kontribusi layanan Cloud bagi pendapatan PT XYZ pada tahun 2014 hanya mencapai 52\% dari target yang harus dicapai Salah satu akar masalah atas tidak tercapainya target pendapatan tersebut adalah belum adanya standar desain layanan Cloud. Sebagai pemegang sertifikat ISO/IEC 20000, PT XYZ dituntut untuk melakukan perbaikan manajemen layanan secara berkesinambungan, termasuk dalam tahap desain layanan. Penelitian ini bertujuan merancang standar desain layanan Cloud di PT XYZ dengan menggunakan kerangka kerja manajemen layanan TI, yaitu Information Technology Infrastructure Library (ITIL) versi 3 dan Microsoft Operation Framework (MOF) 4.0, arsitektur acuan layanan Cloud, dan panduan penerapan ISO/IEC 20000 untuk layanan Cloud. Hasil penelitian ini adalah standar desain layanan berupa aliran proses desain dan template dokumentasi desain yang direkomendasikan dalam pengelolaan layanan Cloud PT XYZ.
\end{abstract}

Kata kunci: Layanan Cloud, Information Technology Service Management, ISO/IEC 20000, Information Technology Infrastructure Library, Microsoft Operation Framework 


\section{PENDAHULUAN}

PT XYZ adalah salah satu perusahaan penyedia layanan teknologi informasi dan komunikasi data di Indonesia. PT XYZ menyediakan layanan konektivitas, internet dan layanan Teknologi Informasi (TI) untuk pelanggan korporat di segmen perbankan, manufaktur, resources, supply chain, telekomunikasi, dan pemerintahan. Dalam rangka mencapai visi dan misinya untuk menjadi ICT Solution Provider terdepan di Indonesia, PT XYZ menerapkan tata kelola layanan TI melalui peraihan sertifikat ISO/IEC 20000 dan mencanangkan peningkatan penetrasi pasar layanan Cloud sebagai salah satu inisiatif strategis. Meskipun demikian, data menunjukkan bahwa pencapaian target layanan Cloud pada kenyataannya belum memenuhi harapan yang telah ditetapkan. Pendapatan dari sektor layanan Cloud belum mencapai target (lihat Gambar 1) dan sebagian target indikator kinerja pun belum dapat dipenuhi (lihat Tabel 1).

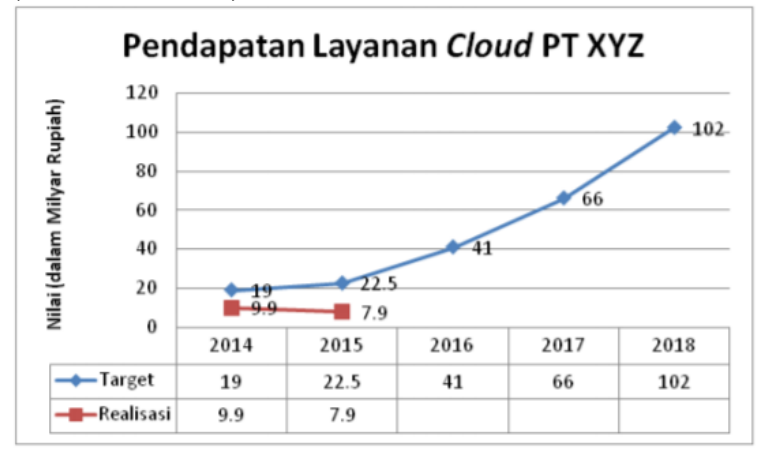

Gambar 1 Pencapaian Pendapatan Layanan Cloud (Sumber: (PT XYZ, 2014b; PT XYZ, 2015), telah diolah kembali)

Salah satu faktor penyebab tidak tercapainya target pendapatan layanan Cloud adalah kurang optimalnya manajemen layanan Cloud di PT XYZ. Hal ini disebabkan belum adanya standar desain layanan Cloud. Hasil survei kebutuhan layanan TI yang diselenggarakan PT XYZ kepada para pelanggannya menunjukkan bahwa aspek desain layanan menjadi faktor penting yang menjadi konsideran mereka dalam memilih penyedia layanan Cloud (PT XYZ, 2015f).

Oleh sebab itu, pertanyaan penelitian yang diajukan adalah "Bagaimana standar desain layanan Cloud PT XYZ yang sesuai dengan syarat sistem manajemen layanan TI menurut ISO/IEC 20000?”. Tujuan penelitian ini adalah mengembangkan standar desain layanan Cloud yang sesuai dengan syarat sistem manajemen layanan TI menurut ISO/IEC 20000 dan memberikan rekomendasi penerapan standar tersebut untuk meningkatkan kualitas layanan Cloud di PT XYZ.

Tabel 1 ARPU, Win Rate, dan Efisiensi Siklus Penjualan Layanan Cloud.

\begin{tabular}{|c|c|c|c|c|}
\hline \multirow[t]{2}{*}{ Aspek } & \multicolumn{2}{|l|}{2014} & \multicolumn{2}{|l|}{2015} \\
\hline & Target & Realisasi & Target & $\begin{array}{l}\text { Realisasi s.d. } \\
\text { Q2 } 2015\end{array}$ \\
\hline ARPU & Lebih besar Rp 100 juta & Rp 25 juta & Lebih besar dari Rp 100 juta & Rp 34 juta \\
\hline Win Rate & $25 \%$ & $15 \%$ & Lebih besar dari $25 \%$ & $37 \%$ \\
\hline $\begin{array}{l}\text { Durasi } \\
\text { Siklus } \\
\text { Penjualan }\end{array}$ & 3 bulan & $\begin{array}{l}\text { Lebih dari } 3 \\
\text { bulan }\end{array}$ & 3 bulan & 4 bulan \\
\hline
\end{tabular}

(Sumber: (PT XYZ, 2014; PT XYZ, 2015b; PT XYZ, 2015a), telah diolah kembali)

\section{KAJIAN LITERATUR}

Bagian ini membahas beberapa literatur yang relevan dengan penelitian, yaitu literatur mengenai layanan teknologi informasi (TI), tahapan desain dalam konteks manajemen layanan TI beserta kerangka kerjanya, arsitektur acuan layanan Cloud, dan standar ISO/IEC 20000.

\section{Cloud Sebagai Layanan Teknologi Informasi (TI)}

Layanan TI adalah layanan yang mengkombinasikan kapabilitas TI, sumber daya manusia (SDM), dan proses untuk mengantarkan layanan ke pengguna berdasarkan perjanjian tingkat layanan yang telah disepakati (Office of Government Commerce, 2007; Gartner, 2013; Mora, Raisinghani, O'Connor, Gomez, \& Gelman, 2014). Layanan Cloud adalah layanan TI yang memungkinkan akses via jaringan ke sekumpulan sumber daya virtual atau fisik sebagai kapabilitas TI yang dapat diskalakan dan bersifat elastis melalui proses administrasi dan provisi secara mandiri 
sesuai kebutuhan (Buyya, Yeo, Venugopal, Broberg, \& Brandic, 2009; Marston, Li, Bandyopadhyay, Zhang, \& Ghalsasi, 2010). Karakteristik utama layanan Cloud meliputi virtualisasi (Vouk, 2008; Marston, Li, Bandyopadhyay, Zhang, \& Ghalsasi, 2010), swalayan berdasarkan kebutuhan (Mell \& Grance, 2011; ISO/IEC, 2014), akses melalui jaringan (Mell \& Grance, 2011; ISO/IEC, 2014), provisi dan pengaturan skalabilitas secara cepat dan dinamis (Mell \& Grance, 2011; ISO/IEC, 2014), layanan yang dapat diukur (Carlin \& Curran, 2012), penggabungan sumber daya (Mell \& Grance, 2011; ISO/IEC, 2014), dan multi-penyewa (Marston, Li, Bandyopadhyay, Zhang, \& Ghalsasi, 2010; Youssef, 2012).

\section{Tahap Desain dalam Manajemen Layanan TI}

Manajemen Layanan TI (MLTI) adalah segenap proses pengelolaan kualitas dan penyediaan layanan TI agar layanan TI tersebut tetap dapat digunakan pelanggan sesuai dengan kesepakatan tingkat layanan (SLA) dan mampu mendukung pencapaian tujuan bisnis organisasi di sisi pelanggan (Tan, Cater-Steel, \& Toleman, 2009; Marrone \& Kolbe, 2010; Marrone \& Kolbe, 2011; Conger, Winniford, \& EricksonHarris, 2008; Pollad, Gupta, \& Satzinger, 2010; Proehl, Erek, Limbach, \& Ruediger, 2013). MLTI menggunakan pendekatan berbasis proses di seluruh tahapannya (Marrone \& Kolbe, 2011; Hochstein, Tamm, \& Brenner, 2005), berfokus tidak hanya pada aspek teknis TI, melainkan ke seluruh aspek layanan TI (Marrone \& Kolbe, 2011; Pollard \& Cater-Steel, 2009), serta menekankan pada perbaikan yang berkesinambungan (continuous improvement) (Tan, Cater-Steel, \& Toleman, 2009). Aspek desain adalah salah satu tahapan dalam manajemen layanan TI di berbagai kerangka kerja MLTI (Mora, Raisinghani, \& Gelman, 2012). Aspek desain pada ISO/IEC 20000 disebutkan pada klausul kelima dari sembilan klausul yang tersedia pada standar tersebut (ISO \& IEC, 2011). ISO/IEC juga telah menyediakan panduan penerapan ISO/IEC 20000 secara khusus untuk layanan Cloud melalui dokumen ISO/IEC TR 200009:2015. Desain sebagai sebuah proses dapat dimaknai sebagai aktivitas intelektual untuk mentransformasikan kebutuhan layanan ke dalam spesifikasi layanan sehingga dapat dilanjutkan ke tahap pengembangan layanan tersebut. Keluaran dari proses tersebut adalah dokumentasi desain yang menjelaskan seluruh kebutuhan layanan (Mora, Raisinghani, O'Connor, Gomez, \& Gelman, 2014). Secara spesifik, terdapat beberapa faktor sukses kritikal dalam desain layanan Cloud pada perspektif penyedia layanan, yaitu penjaminan keamanan informasi, ketersediaan standar interoperabilitas dengan sistem on-premise atau on-cloud lainnya, memiliki status hukum yang jelas dan dilindungi regulasi nasional atau internasional, dan penjaminan quality of service (QoS) (Marston, Li, Bandyopadhyay, Zhang, \& Ghalsasi, 2010; Rimal, Jukan, Katsaros, \& Goeleven, 2010).

Dalam penelitian ini, penulis menggunakan dua kerangka kerja MLTI, yaitu Information Technology Infrastructure Library versi 3 (ITIL V3) dan Microsoft Operation Framework versi 4 (MOF V4). ITIL V3 memfasilitasi proses desain pada tahap Service Design, sementara MOF V4 memfasilitasi proses desain pada fase Deliver, yaitu pada Service Management Function (SMF) Envision dan Project Planning. ITIL V3 dan MOF V4 dipilih karena PT XYZ telah menggunakan ITIL V3 pada saat implementasi ISO/IEC 20000, deskripsi proses desain dan arsitektur desain pada kedua kerangka kerja ini berada pada tingkat "moderate-tostrong", dan MOF V4 memiliki kumpulan template prosedur, pedoman, dan rekomendasi yang bersifat gratis sebagai alat bantu praktis untuk mengimplementasikan konsep desain 
layanan menurut ITIL V3 (Mora, Raisinghani, O'Connor, Gomez, \& Gelman, 2014; Microsoft Corporation, 2012).

\section{Arsitektur Acuan Layanan Cloud}

Proses desain layanan Cloud membutuhkan pemahaman terhadap layanan ini secara arsitektural (Mora, Raisinghani, O'Connor, Gomez, \& Gelman, 2014). Arsitektur layanan Cloud merupakan panduan prinsip-prinsip yang digunakan dalam proses desain dan implementasi layanan Cloud (Liu, Zhang, Hu, \& He, 2012; Zhang \& Zhou, 2009) sekaligus untuk meningkatkan kualitas manajemen layanannya (Arabalidousti, Nasiri, \& Davoudi, 2014; Amanatullah, Lim, Ipung, \& Juliandi, 2013). Maier, Emery, dan Hilliard (2004) dalam (Mora, Raisinghani, O'Connor, Gomez, \& Gelman, 2014) mendefinisikan arsitektur layanan TI sebagai representasi konseptual sistem layanan yang menjelaskan komponen esensial dan keterkaitannya satu sama lain dengan cara yang terorganisir dan hierarkis. Berbagai konsep arsitektur acuan layanan Cloud telah diajukan dalam banyak penelitian (Liu, Zhang, Hu, \& He, 2012), tetapi Breivold, Crnkovic, Radosevic, \& Balatinac (2014) menyarankan setiap organisasi untuk meninjau dan membandingkan arsitektur acuan tersebut dengan konteks dan isu utama organisasi yang bersangkutan agar dapat menerapkannya dalam proses desain layanan Cloud. Penulis membandingkan empat model arsitektur acuan layanan Cloud (lihat Tabel 2) dengan konteks dan isu utama di PT XYZ untuk menghasikan model arsitektur layanan Cloud yang menjadi landasan pengembangan standar proses desain layanan ini, yaitu ISO/IEC 17789 (ISO/IEC, 2014), NIST CCRA (Liu, et al., 2011), arsitektur acuan layanan Cloud Berdasarkan PRM-IT, eTOM, \& COBIT5 (Arabalidousti, Nasiri, \& Davoudi, 2014), dan arsitektur acuan layanan Cloud berbasis SOA (Liu, Zhang, $\mathrm{Hu}, \& \mathrm{He}, 2012)$.
Dalam penelitian ini penulis memilih ISO/IEC 17789 sebagai acuan utama dalam mendefinisikan komponen-komponen layanan Cloud setelah mempertimbangkan keselarasannya dengan kondisi dan isu utama di organisasi PT XYZ.

\section{Kerangka Kerja Teoretis}

Berdasarkan studi literatur yang telah diuraikan, penulis membangun kerangka kerja teoretis sebagai acuan penelitian seperti diilustrasikan pada Gambar 2.

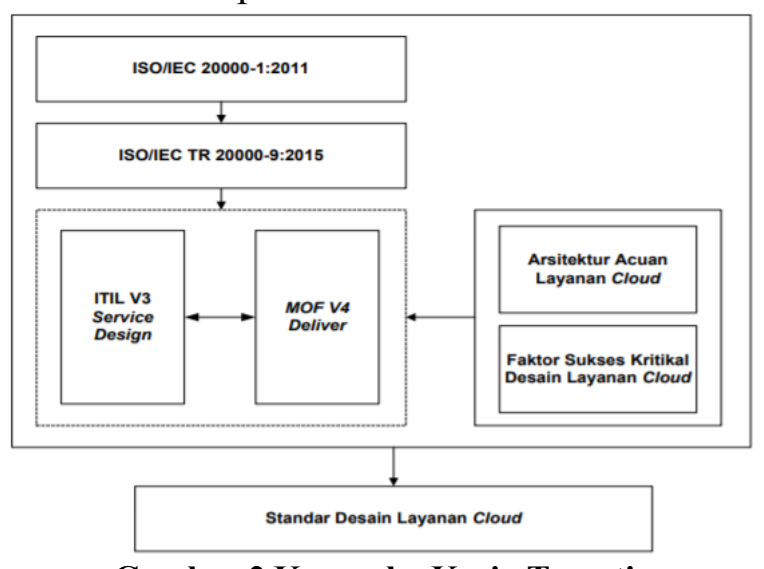

Gambar 2 Kerangka Kerja Teoretis

\section{METODE PENELITIAN}

Penelitian ini berupa studi kasus (case study research) yang menjadikan PT XYZ sebagai organisasi objek penelitian. Penelitian ini bertujuan mengembangkan kebijakan mengenai standar kerja sehingga dapat dikategorikan pula sebagai policy research. Urutan tahap penelitian secara keseluruhan beserta penjelasannya adalah sebagai berikut:

\section{a. Identifikasi Masalah dan Akarnya}

Identifikasi masalah dilakukan dengan menganalisis kondisi organisasi berdasarkan data harapan dan realita yang didapatkan melalui dokumen resmi perusahaan dan wawancara pendahuluan. Kesenjangan antara realita dan harapan dianalisis dengan menggunakan fishbone diagram untuk menemukan akar masalah yang dipilih sebagai sumber pertanyaan penelitian. 


\section{b. Studi Literatur}

Studi literatur dilakukan untuk mempelajari teori, metodologi, dan penelitian sebelumnya yang terkait dengan standar dan kerangka kerja MLTI, desain layanan Cloud, dan arsitektur acuannya untuk menghasilkan sebuah kerangka kerja teoretis penelitian ini.

\section{c. Analisis Model Kapabilitas dan Penyebaran Layanan Cloud}

Analisis model kapabilitas dan penyebaran layanan Cloud dilakukan berdasarkan katalog layanan Cloud PT $\mathrm{XYZ}$ dan arsitektur acuan layanan Cloud melalui studi dokumen dan FGD untuk menghasilkan model kapabilitas dan penyebaran layanan Cloud yang relevan dengan kondisi organisasi PT XYZ.

\section{d. Analisis Pemangku Kepentingan (stakeholder) Layanan Cloud dan Perannya}

Analisis pemangku kepentingan layanan Cloud beserta perannya masing-masing dilakukan berdasarkan kondisi riil pemangku kepentingan layanan Cloud di PT XYZ, dokumen perusahaan, dan arsitektur acuan layanan Cloud. Studi dokumen dan FGD dipilih sebagai teknik untuk menghasilkan pemetaan pemangku kepentingan layanan Cloud yang relevan dengan kondisi organisasi di PT XYZ.

\section{e. Analisis Komponen Layanan Cloud}

Analisis komponen layanan Cloud dilakukan berdasarkan dokumen perusahaan dan arsitektur acuan layanan Cloud melalui studi dokumen dan FGD untuk menghasilkan daftar komponen layanan Cloud yang relevan dengan kondisi organisasi di PT XYZ.

\section{f. Analisis Kebutuhan Standar Desain Layanan Cloud}

Berdasarkan hasil analisis model kapabilitas dan penyebaran layanan Cloud, analisis pemangku kepentingan layanan Cloud, dan analisis komponen layanan Cloud, dilakukan analisis kebutuhan standar desain layanan Cloud dengan menggunakan panduan dari ITIL V3 dan MOF V4. Keluaran dari proses ini adalah rekomendasi standar proses desain dan template dokumentasi desain layanan Cloud.

\section{g. Validasi dan Perbaikan Standar Desain Layanan Cloud}

Rekomendasi standar proses desain dan template dokumentasinnya divalidasi dilakukan dengan melalui proses wawancara. Semua umpan balik akan diolah untuk memperbaiki draft standar yang telah dibangun. Keluaran dari tahap ini adalah standar desain yang sudah divalidasi.

\section{h. Penarikan Kesimpulan dan Saran}

Berdasarkan standar desain layanan yang telah dihasilkan, dilakukan penarikan kesimpulan yang meliputi rekapitulasi temuan utama, implikasi manajerial dari temuan tersebut, dan pemberian saran untuk penelitian selanjutnya (Sekaran \& Bougie, 2013). Pengumpulan data dilakukan sesuai kebutuhan pada tiap tahap penelitian, baik berupa data primer maupun sekunder. Data primer dikumpulkan melalui wawancara dan FGD, sementara data sekunder dikumpulkan melalui studi terhadap dokumen internal perusahaan, jurnal dan buku ilmiah yang relevan dengan penelitian ini.

\section{HASIL DAN PEMBAHASAN}

Empat bagian pertama adalah analisis terhadap kondisi faktual di PT XYZ dengan menggunakan pendekatan sesuai metodologi penelitian, yaitu model kapabilitas dan penyebaran layanan Cloud, pemangku kepentingan layanan Cloud, serta komponen horizontal dan vertikal dalam desain layanan Cloud. Sementara itu, bagian terakhir adalah pembangunan standar desain layanan Cloud berdasarkan hasil analisis pada empat bagian sebelumnya.

1. Model Kapabilitas dan Penyebaran Layanan Cloud 
Jurnal Instruksional, Volume 1, Nomor 2, April 2020116

ISSN: 2686-5645

Berdasarkan FGD yang dilakukan, layanan Cloud di PT XYZ dapat dipetakan dengan menggunakan matriks tipe kapabilitas dan model penyebaran layanan Cloud sebagaimana dicantumkan pada Tabel 3.

Tabel 3 Matriks Kapabilitas Layanan Cloud

\begin{tabular}{|c|c|c|c|c|}
\hline \multirow{2}{*}{ Kategori Layanan Cloud } & \multicolumn{3}{|c|}{ Tipe kapabilitas Cloud } & \multirow{2}{*}{ Keterangan } \\
\hline & Infrastruktur & Platform & Aplikasi & \\
\hline IaaS - Public Cloud & $\mathrm{X}$ & & & Sudah operasional \\
\hline IaaS - Private Cloud & $\mathrm{X}$ & & & Sudah operasional \\
\hline Backup as a Service & $\mathrm{X}$ & & & $\begin{array}{l}\text { Proses serah terima dari tim } \\
\text { pengembangan ke tim operasional }\end{array}$ \\
\hline $\begin{array}{l}\text { Disaster Recovery as a } \\
\text { Service }\end{array}$ & $\mathrm{x}$ & & & $\begin{array}{l}\text { Proses serah terima dari tim } \\
\text { pengembangan ke tim operasional }\end{array}$ \\
\hline SaaS-Managed Mail & $\mathrm{X}$ & & $\mathrm{X}$ & Sudah operasional \\
\hline SaaS-Market Place & & & $\mathrm{X}$ & $\begin{array}{l}\text { Layanan ini berada pada tahap } \\
\text { perencanaan }\end{array}$ \\
\hline Security as a Service & $\mathrm{X}$ & & $\mathrm{X}$ & $\begin{array}{l}\text { Layanan ini berada pada tahap } \\
\text { perencanaan }\end{array}$ \\
\hline Federated Cloud & $\mathrm{x}$ & & & $\begin{array}{l}\text { Layanan ini berada pada tahap } \\
\text { perencanaan }\end{array}$ \\
\hline
\end{tabular}

Tabel 3 mencantumkan layanan Backup as a Service, Disaster Recovery (DR) as a Service, Security as a Service, dan Federated Cloud yang tidak secara spesifik dinamakan sebagai SaaS, PaaS, dan IaaS, tetapi tetap dapat dipetakan berdasarkan kapabilitas Cloud sesuai konsep yang diajukan ISO/IEC 17788. Sehubungan dengan penyebaran layanan, saat ini PT XYZ melayani Private Cloud dan Public Cloud. PT XYZ memiliki roadmap untuk mengembangkan Hybrid Cloud. Tabel 4 mengilustrasikan template matriks yang dibutuhkan untuk mengidentifikasi layanan Cloud di PT XYZ berdasarkan kapabilitas dan penyebaran pada tiap jenis layanan Cloud. Setiap kolom selain nama layanan diberi tanda " $x$ " jika berlaku pada layanan yang dimaksud.

Tabel 4 Matriks Identifikasi Jenis Layanan Cloud

\begin{tabular}{|c|c|c|c|c|c|c|c|}
\hline \multirow{2}{*}{$\begin{array}{c}\text { Nama } \\
\text { Layanan }\end{array}$} & \multicolumn{3}{|c|}{ Tipe Kapabilitas Cloud } & \multicolumn{3}{c|}{ Model Penyebaran Cloud } \\
\cline { 2 - 7 } & Infrastruktur & Platform & Aplikasi & Public & Private & Hybrid & Community \\
\hline & & & & & & & \\
\hline
\end{tabular}

\section{Pemangku Kepentingan Layanan Cloud}

Pemangku kepentingan layanan Cloud di PT XYZ dipetakan berdasarkan ISO/IEC 17789. FGD yang dilakukan memfokuskan pembahasan mengenai peran Cloud Service Provider dan Cloud Service Partner. Rekapitulasi pemetaan peran dengan struktur organisasi PT XYZ saat ini dicantumkan pada Tabel 5.

Tabel 5 Pemetaan Peran Pemangku Kepentingan Layanan Cloud

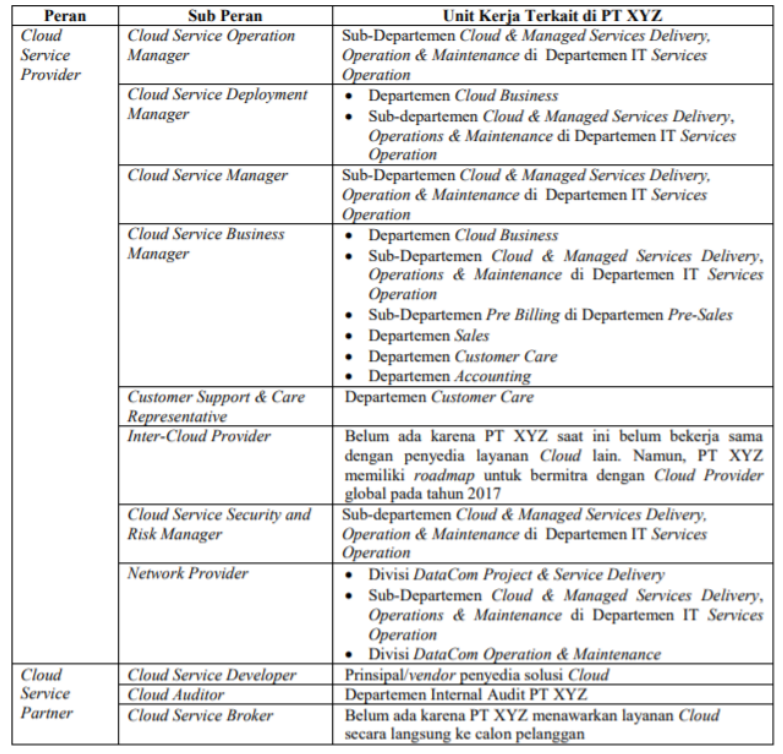

Berdasarkan pemetaan peran pada Tabel 5, dilakukan analisis kesenjangan untuk mengetahui aktivitas-aktivitas tiap peran yang belum dijalankan secara optimal terkait dengan ketersediaan dan rencana pemenuhan kompetensi SDM di PT XYZ dalam konteks pelayanan Cloud. Hasil analisis menunjukkan bahwa PT XYZ belum memenuhi kompetensi perencanaan kapasitas, dasar pengetahuan layanan Cloud untuk unit kerja Customer Care, keamanan informasi, dan manajemen risiko.

\section{Komponen Horizontal dalam Desain Layanan Cloud}

Berdasarkan komponen horizontal dalam arsitektur acuan layanan Cloud yang tercantum pada Tabel 2, dilakukan sesi FGD untuk mengevaluasi ketersediaan komponen tersebut di PT XYZ sebagai salah satu rujukan dalam penyusunan rekomendasi standar desain layanan Cloud. Rekapitulasinya ditampilkan pada Tabel 6.

Berdasarkan Tabel 6, PT XYZ telah mengimplementasikan aspek administrasi teknis layanan yang komprehensif mulai dari user layer, access layer, hingga service layer melalui penggunaan VMware vCloud Director dan UCS Director. Meskipun demikian, masih terdapat kelemahan pada aspek administrasi bisnis yang ditandai dengan tidak adanya antar muka berbasis 
Cloud bagi manajer bisnis pelanggan untuk mengelola keberlangganan layanan Cloud secara self-service dan kurang selarasnya fitur kapabilitas bisnis yang direpresentasikan oleh BSS dengan spesifikasi dan kebutuhan layanan Cloud.

Tabel 6 Implementasi Komponen Horizontal Layanan Cloud di PT XYZ

\begin{tabular}{|c|c|c|}
\hline Komponen & Sub Komponen & Implementasi \\
\hline \multirow[t]{3}{*}{ Userlayer } & User function & Aplikasi berbasis web (Vmware vCloud Director, remote desktop, Zimbra) \\
\hline & Business function & $\begin{array}{l}\text { PT XYZ belum memiliki business function berbasis Cloud yang menganut } \\
\text { prinsip self-service }\end{array}$ \\
\hline & $\begin{array}{l}\text { Administrator } \\
\text { function }\end{array}$ & Aplikasi berbasis web (VMware vCloud Director, Zimbra) \\
\hline \multirow[t]{4}{*}{$\begin{array}{l}\text { Access } \\
\text { layer }\end{array}$} & Service access & $\begin{array}{l}\text { Otentikasi dan otorisasi menggunakan aplikasi web VMware vCloud } \\
\text { Director dan Zimbra }\end{array}$ \\
\hline & Business access & $\begin{array}{l}\text { Sistem otentikasi single-sign-on (SSO) dan portal User Management } \\
\text { Center (UMC) yang bertindak sebagai sistem otorisasi bagi tim sales PT } \\
\text { XYZ yang akan mengakses kapabilitas bisnis di internal PT XYZ }\end{array}$ \\
\hline & $\begin{array}{l}\text { Administration } \\
\text { access }\end{array}$ & $\begin{array}{l}\text { Otentikasi dan otorisasi melalui aplikasi VMware vCloud Director dan } \\
\text { UCS Director }\end{array}$ \\
\hline & $\begin{array}{l}\begin{array}{l}\text { Development } \\
\text { access }\end{array} \\
\end{array}$ & $\begin{array}{l}\text { Otentikasi dan otorisasi melalui remote desktop, akses fisik (tidak ada } \\
\text { otentikasi pada skenario akses fisik), PT XYZ belum memiliki lingkungan } \\
\text { pengembangan dan pengujian }\end{array}$ \\
\hline \multirow[t]{4}{*}{$\begin{array}{l}\text { Service } \\
\text { layer }\end{array}$} & $\begin{array}{l}\begin{array}{l}\text { Service } \\
\text { capabilities }\end{array} \\
\end{array}$ & Kapabilitas layanan sesuai dengan yang ditawarkan \\
\hline & \begin{tabular}{|l|}
$\begin{array}{l}\text { Business } \\
\text { capabilities }\end{array}$ \\
\end{tabular} & $\begin{array}{l}\text { Fitur/fungsionalitas Aplikasi Business Support System (BSS) belum selaras } \\
\text { dengan spesifikasi layanan Cloud }\end{array}$ \\
\hline & $\begin{array}{l}\text { Administration } \\
\text { capabilities }\end{array}$ & $\begin{array}{l}\text { instruksi kerja provisioning, fitur provisioning, dan fitur pemantauan } \\
\text { performansi dan kapasitas layanan Cloud dan sebagainya yang ada di OSS }\end{array}$ \\
\hline & $\begin{array}{l}\text { Service } \\
\text { orchestration }\end{array}$ & Orkestrasi dilakukan oleh Vyware VCloud Director, UCS Director \\
\hline \multirow{2}{*}{$\begin{array}{l}\text { Resource } \\
\text { Abstraction } \\
\& \text { Control }\end{array}$} & $\begin{array}{l}\text { Resource } \\
\text { abstraction }\end{array}$ & Sumber daya virtual meliputi vDC, vCPU, vRAM, dan vSAN \\
\hline & Resource control & Vmware vSphere \\
\hline $\begin{array}{l}\text { Physical } \\
\text { Resource }\end{array}$ & Physical resource & Server, storage, dan sumber daya jaringan \\
\hline
\end{tabular}

\section{Komponen Vertikal dalam Desain Layanan Cloud}

Berdasarkan komponen vertikal dalam arsitektur acuan layanan Cloud yang tercantum pada Tabel 2, dilakukan sesi FGD untuk mengevaluasi ketersediaan komponen tersebut di PT XYZ sebagai salah satu rujukan dalam penyusunan rekomendasi standar desain layanan Cloud. Referensi untuk kedua komponen ini diambil dari ITIL V3. Rekapitulasinya ditampilkan pada Tabel 7.

Berdasarkan Tabel 7, PT XYZ belum memiliki sistem yang terintegrasi dalam hal otentikasi dan otorisasi untuk mengakses sumber daya Cloud, belum merencanakan aspek portability dan interoperability, tidak memiliki laboratorium pengembangan dan pengujian yang terpisah dari lingkungan operasional, serta tidak melakukan desain sistem pendukung operasional dan bisnis (OSS dan BSS) beserta integrasinya secara komprehensif saat pengembangan layanan dilakukan.
Tabel 7 Implementasi Komponen Vertikal Layanan Cloud di PT XYZ

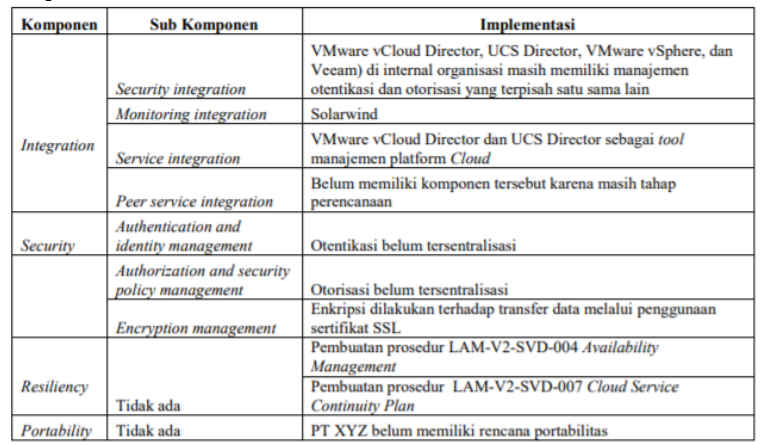

5. Kebutuhan Standar Desain Layanan Cloud

Ruang lingkup kebutuhan standar desain layanan Cloud meliputi aliran proses desain dan standar/template dokumentasi desain. Penulis memanfaatkan hasil analisis model kapabilitas dan penyebaran layanan, pemangku kepentingan, serta komponen horizontal dan vertikal layanan Cloud yang telah dijelaskan sebelumnya dalam menyusun kebutuhan standar tersebut. Penulis mengadaptasi aliran proses desain layanan TI secara umum menurut ITIL V3 pada tahap Service Design yang meliputi proses analisis kebutuhan layanan, desain solusi layanan, evaluasi solusi alternatif, pengadaan produk atau solusi layanan terpilih, dan pengembangan solusi layanan, sebagai baseline dalam penyusunan standar desain layanan Cloud di PT XYZ. Tahap analisis kebutuhan layanan dimulai dengan identifikasi peluang bisnis melalui beberapa aktivitas pada Tabel 8. Aktivitas identifikasi peluang bisnis mengacu ke prosedur internal di PT XYZ (PT XYZ, 2014a). Aktivitas berikutnya adalah penentuan visi, yaitu menguraikan dengan jelas dan ringkas tentang kondisi yang diharapkan terjadi di sisi PT XYZ pasca implementasi layanan Cloud. Aktivitas-aktivitas selanjutnya pada tahap analisis kebutuhan ini meliputi beberapa jenis analisis pada Tabel 9. Semua keluaran pada tahap analisis kebutuhan dicatat pada dokumen yang disebut Dokumen Visi. 
Tabel 8 Identifikasi Peluang Bisnis

\begin{tabular}{|l|l|l|}
\hline \multicolumn{1}{|c|}{ Item } & \multicolumn{1}{|c|}{ Referensi } & \multicolumn{1}{c|}{ Penanggung Jawab } \\
\hline Pemahaman terhadap rencana bisnis (RKUP) & Prosedur LAP-V1-PDM-006 & $\begin{array}{l}\text { Cloud Service Business } \\
\text { Manager }\end{array}$ \\
\hline Identifikasi Kebutuhan Pelanggan & Prosedur LAP-V1-PDM-006 & Tim Sales \\
\hline Riset dan Analisis Pasar & $\begin{array}{l}\text { Prosedur LAP-V1-PDM-006 } \\
\text { Buku Putih Cloud Services } \\
\text { 2011 PT XYZ }\end{array}$ & $\begin{array}{l}\text { Cloud Service Business } \\
\text { Manager }\end{array}$ \\
\hline $\begin{array}{l}\text { Peninjauan performansi layanan operasional } \\
\text { saat ini }\end{array}$ & Prosedur LAP-V1-PDM-006 & $\begin{array}{l}\text { Cloud Service Business } \\
\text { Manager }\end{array}$ \\
\hline
\end{tabular}

Tabel 9 Penentuan Visi dan Aktivitas Analisis Kebutuhan Layanan

\begin{tabular}{|c|c|c|}
\hline Item & Referensi & Penanggung Jawab \\
\hline Penentuan Visi & $\begin{array}{l}\text { "Vision Statement" dari MOF V } 4 \text { Job Aid: Vision } \\
\text { Scope }\end{array}$ & $\begin{array}{l}\text { Cloud Service Business } \\
\text { Manager }\end{array}$ \\
\hline Analisis Manfaat & $\begin{array}{l}\text { Modifikasi dari "Benefit Analysis" MOF V4 Job Aid: } \\
\text { Vision Scope (Microsoft Corporation, 2008) }\end{array}$ & $\begin{array}{l}\text { Cloud Service Business } \\
\text { Manager }\end{array}$ \\
\hline Evaluasi & $\begin{array}{l}\text { MOF V4 SMF Envision (Microsoft Corporation, } \\
\text { 2008b), MOF V4 SMF Governance, Risk, \& } \\
\text { Compliance (Microsoft Corporation, 2008d), Peran } \\
\text { Cloud Sevice Security \& R Risk Manager (ISO/IEC, } \\
\text { 2014), ISO/EC } 17789 \text { (ISO/EC, 2014) }\end{array}$ & $\begin{array}{l}\text { Cloud Service Security and } \\
\text { Risk Manager }\end{array}$ \\
\hline $\begin{array}{l}\text { Analisis Pemangku } \\
\text { Kepentingan Layanan }\end{array}$ & $\begin{array}{l}\text { Pemangku Kepentingan menurut ISO/IEC } 17789 \\
\text { (ISO/IEC, 2014)), Aspek desain menurut ITIL V3 }\end{array}$ & $\begin{array}{l}\text { Cloud Service Business } \\
\text { Manager }\end{array}$ \\
\hline Cloud & (Cabinet Office, 2011) & \\
\hline $\begin{array}{l}\text { Analisis kebutuhan } \\
\text { tipe kapabilitas dan } \\
\text { penyebaran layanan } \\
\text { Cloud }\end{array}$ & $\begin{array}{l}\text { Arsitcktur acuan layanan Cloud (Tabel 2), ISO/IEC TR } \\
\text { 20000-9:2015 (ISO/IEC, 2015) }\end{array}$ & $\begin{array}{l}\text { Cloud Service Business } \\
\text { Manager }\end{array}$ \\
\hline $\begin{array}{l}\text { Analisis kebutuhan } \\
\text { non fungsional }\end{array}$ & $\begin{array}{l}\text { Arsitcktur acuan layanan Cloud (Tabel 2), ISO/IEC TR } \\
20000-9: 2015 \text { (ISO/IEC, 2015) }\end{array}$ & $\begin{array}{l}\text { Cloud Service Business } \\
\text { Manager }\end{array}$ \\
\hline
\end{tabular}

Dokumen Visi yang berisikan hasil analisis kebutuhan layanan Cloud menjadi rujukan dalam tahap berikutnya, yaitu tahap desain solusi layanan. Desain solusi terdiri atas dua level, yaitu desain lojik dan desain fisik. Desain lojik berfokus pada pemetaan komponen layanan beserta keterkaitannya satu sama lain. Sementara itu, desain fisik menyasar produk dan teknologi yang akan digunakan untuk mengimplementasikan komponen layanan dan interkoneksinya secara fisik. Proses pengadaan kandidat produk tersebut diawali dengan mekanisme proof-ofconcept $(\mathrm{PoC})$ untuk mengevaluasi kelayakan dari sisi teknis. Desain solusi layanan secara keseluruhan didokumentasikan pada Dokumen Desain Solusi. Rekapitulasi tahap desain solusi dapat dilihat pada Tabel 10.

Tabel 10 Desain Solusi Layanan

\begin{tabular}{|l|l|l|}
\hline \multicolumn{1}{|c|}{ Item } & \multicolumn{1}{|c|}{ Referensi } & \multicolumn{1}{|c|}{ Penanggung Jawab } \\
\hline $\begin{array}{l}\text { Desain Lojik Layanan } \\
\text { Cloud }\end{array}$ & $\begin{array}{l}\text { Arsitektur acuan layanan Cloud, MOF V4 SMF } \\
\text { Envision (Microsoft Corporation, 2008c) } \\
\text { IISO/EC 17789 (ISO/IEC, 2014) } \\
\text { ISO/IEC TR 20000-9:2015 (ISO/EC, 2015) }\end{array}$ & $\begin{array}{l}\text { Cloud Service Business } \\
\text { Manager }\end{array}$ \\
\hline $\begin{array}{l}\text { Desain Fisik Layanan } \\
\text { Cloud }\end{array}$ & $\begin{array}{l}\text { MOF V4 Job Aid: Functional Spesification (Microsoft } \\
\text { Corporation, 2008a) } \\
\text { TIIL Service Design (Cabinet Office, 2011) }\end{array}$ & $\begin{array}{l}\text { Cloud Service Business } \\
\text { Manager }\end{array}$ \\
\hline $\begin{array}{l}\text { Evaluasi Produk dan } \\
\text { Teknologi }\end{array}$ & $\begin{array}{l}\text { SMF Project Planning pada MOF V4 (Microsoft } \\
\text { Corporation, 2008c) } \\
\text { ITIL V3 Service Design (Cabinet Office, 2011) }\end{array}$ & $\begin{array}{l}\text { Cloud Service Business } \\
\text { Manager }\end{array}$ \\
\hline
\end{tabular}

Setelah melalui rangkaian $\mathrm{PoC}$ dan pengadaan (procurement), proses pengembangan/penyediaan dilakukan oleh pihak ketiga sebagai penyedia solusi/teknologi. Pelaksanaan pengembangan solusi layanan merupakan salah satu proses individual yang harus menjadi bagian dari rencana proyek implementasi, selain komponen BSS dan OSS-nya. Setiap proyek invidual kemudian dikonsolidasikan dalam satu rencana proyek induk yang selanjutnya menghasilkan jadwal proyek induk (Microsoft Corporation, 2008c). Tahap ini disebut tahap perencanaan proyek implementasi layanan yang menghasilkan Dokumen Perencanaan Proyek Implementasi yang meliputi rencana implementasi individual dan rencana implementasi induk (termasuk jadwalnya).

\section{KESIMPULAN}

Berdasarkan hasil analisis dan pembahasan terkait pengembangan standar desain layanan Cloud di PT XYZ, dapat ditarik kesimpulan berupa aliran proses desain layanan dan dokumen yang dibutuhkan sesuai dengan persyaratan sistem MLTI menurut ISO/IEC 20000. Rekapitulasi standar desain layanan Cloud berupa tahapan yang diuraikan pada Tabel 11.

Tabel 11 Aliran Proses Desain Layanan Cloud

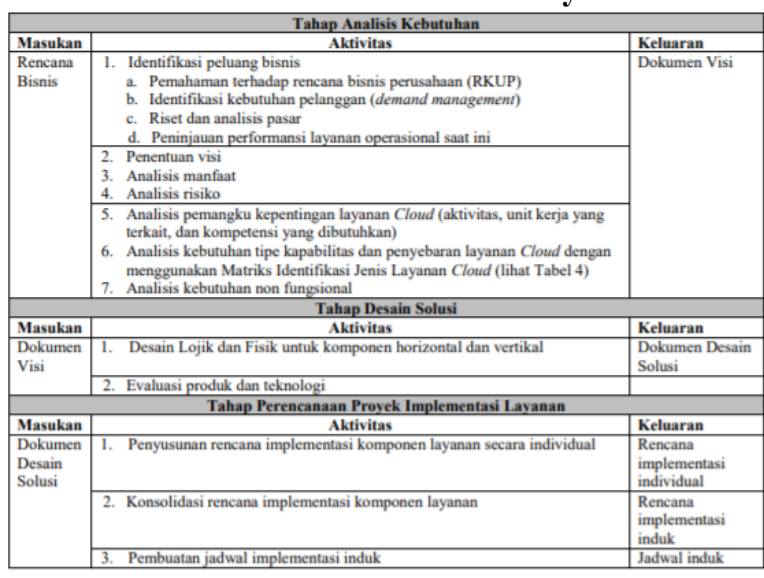

Saran utama berdasarkan hasil analisis dan pembahasan adalah menerapkan standar desain layanan Cloud yang dikembangkan melalui penelitian ini agar mampu menghasilkan desain layanan yang komprehensif. Dengan menggunakan pendekatan pada standar desain ini, dapat direkomendasikan pula beberapa saran perbaikan, yaitu penyusunan proses bisnis dan alat bantu business function berbasis 
Cloud pada user layer yang dapat digunakan secara selfservice oleh pelanggan untuk percepatan proses berlangganan, perbaikan sinkronisasi antara BSS dengan spesifikasi teknis layanan Cloud, pemusatan proses otentikasi dan otorisasi, serta penyediaan laboratorium pengembangan dan pengujian layanan secara terpisah dari lingkungan operasional. Dari sisi SDM, disarankan pula untuk memperkuat kompetensi terkait layanan Cloud terutama untuk tim Customer Care serta memperkuat kompetensi dalam hal perencanaan kapasitas, keamanan informasi, dan manajemen risiko layanan.

\section{REFERENSI}

Amanatullah, Y., Lim, C., Ipung, H. P., \& Juliandi, A. (2013). Toward Cloud Computing Reference Architecture: Cloud Service Management Perspective. 2013 International Conference. ICT for Smart Society (ICISS) .

Arabalidousti, F., Nasiri, R., \& Davoudi, M. R. (2014). Developing A New Architecture to Improve ITSM on Cloud Computing Environment. International Journal on Cloud Computing: Services and Architecture , 1131.

Breivold, H. P., Crnkovic, I., Radosevic, I., \& Balatinac, I. (2014). Architecting for the Cloud: A Systematic Review. IEEE 17th International Conference on Computational Science and Engineering, 312-318.

Buyya, R., Yeo, C. S., Venugopal, S., Broberg, J., \& Brandic, I. (2009). Cloud Computing and Emerging IT Platforms: Vision, Hype, and Reality for Delivering Computing as the 5th Utility. Future Generation Computer Systems , 599-616.

Cabinet Office. (2011). ITIL Service Design. London: The Stationery Office.
Carlin, S., \& Curran, K. (2012). Cloud Computing Technologies. International Journal of Cloud Computing and Services Science , 1 (2), 59-65.

Conger, S., Winniford, M., \& EricksonHarris, L. (2008). Service Management in Operations. Proceedings of the 14th Americas Conference on Information Systems. Canada.

Gartner. (2013). IT Glossary. Retrieved November 30, 2014, from Gartner Website: http://www.gartner.com/it-glossary/itservices

Hochstein, A., Tamm, G., \& Brenner, W. (2005). Service-Oriented IT Management: Benefit, Cost, and Success Factors. Proceedings of the 15th European Conference on Information Systems. Regensburg, Germany.

ISO \& IEC. (2011). Part1: Service Management System Requirements. In I. JTC, ISO/IEC 20000:2011 Information Technology - Service Management (pp. 126). BSI.

ISO/IEC. (2014, October 15). ISO/IEC 17788: Information Technology - Cloud Computing - Overview and vocabulary. pp. $1-10$

ISO/IEC. (2014). ISO/IEC 17789: Information Technology - Cloud Computing - Reference Architecture. Geneva: ISO/IEC.

ISO/IEC. (2015). ISO/IEC TR 20000-9:2015 (Part 9: Guidance on the Application of ISO/IEC 20000-1 to Cloud Services). BSI Standards Limited

Liu, F., Tong, J., Mao, J., Bohn, R., Messina, J., Badger, L., et al. (2011). NIST Cloud 
Computing Reference Architecture. Gaithersburg: National Institute of Standard and Technology.

Liu, J., Zhang, L.-J., Hu, B., \& He, K. (2012). CCRA: Cloud Computing Reference Architecture. IEEE 9th International Conference on Services Computing (pp. 657-665). IEEE

Maier, M., Emery, D., \& Hilliard, R. (2004). ANSI/IEEE 1471 and Systems Engineering. Systems Engineering (pp. 257-270). IEEE.

Marrone, M., \& Kolbe, L. M. (2011). Impact of IT Service Management Frameworks on the IT Organization : An Empirical Study on Benefits, Challenges, and Processes. Business \& Information Systems Engineering, 18.

Marrone, M., \& Kolbe, L. M. (2010). ITIL and The Creation of Benefits : An Empirical Study on Benefits, Challenges, and Process. 18th European Conference on Information Systems , 1-12.

Marston, S., Li, Z., Bandyopadhyay, S., Zhang, J., \& Ghalsasi, A. (2010). Cloud Computing - The business perspective. Decision Support System, 176-188.

Mell, P., \& Grance, T. (2011, September). The NIST Definition of Cloud Computing : Recommendation of the National Institute of Standards and Technology. NIST Special Publication 800-145 . Gaithersburg: National Institute of Standards and Technology

Microsoft Corporation. (2012, July 12). Getting Started with MOF 4.0: An Implementation Guide. Retrieved October 5, 2015, from TechNet Microsoft: https://technet.microsoft.com/enus/library/cc506049.aspx
Microsoft Corporation. (2008b, April). Microsoft Operation Framework 4.0: Envision Service Management Function. Retrieved October 26, 2014, from Microsoft Official Website: http://www.microsoft.com/enus/download/details.aspx?id=17647

Microsoft Corporation. (2008d, April 4). Microsoft Operation Framework 4.0: Governance, Risk, and Compliance Service Management Function. Retrieved October 26, 2014, from Microsoft Official Website: http://www.microsoft.com/enus/download/d etails.aspx?id=17647

Microsoft Corporation. (2008c, April). Microsoft Operation Framework 4.0: Project Planning Service Management Function. Retrieved October 26, 2014, from Microsoft Official Website.

Microsoft Corporation. (2008a). MOF Job Aid: Functional Spesification. Microsoft Corporation

Microsoft Corporation. (2008). MOF Job Aid: Vision Scope. Microsoft.

Mora, M., Raisinghani, M., \& Gelman, O. (2012). A Comparison of Service Design Processes in Relevant International ITSM Models and Standards. Proceedings of SIGSVC Workshop (pp. 12-29). Phoenix: Sprouts

Mora, M., Raisinghani, M., O'Connor, R. V., Gomez, J. M., \& Gelman, O. (2014). An Extensive Review of IT Service Design in Seven International ITSM Processes Frameworks: Part 1. International Journal of Information Technologies and Systems Approach , 83-107.

Office of Government Commerce. (2007, May 30). ITIL V3 Glossary. United 
Kingdom. Pollad, C., Gupta, D., \& Satzinger, J. (2010). Teaching Systems Development : A Compelling Case for Integrating the SDLC with the ITSM Lifecycle. Information Systems Management , 113-122

Pollard, C., \& Cater-Steel, A. (2009). Justifications, Strategies, and Critical Success Factors in Successful ITIL Implementation in U.S and Australian Companies : An Exploratory Study. Information Systems Management , 1-27.

Presiden Republik Indonesia. (2008, Juli 4). Undang-Undang Republik Indonesia Nomor 20 Tahun 2008 tentang Usaha Mikro, Kecil, dan Menengah. Jakarta, Indonesia: Menteri Hukum dan Hak Asasi Manusia Republik Indonesia

Proehl, T., Erek, K., Limbach, F., \& Ruediger, Z. (2013). Topics and Applied Theories in IT Service Management. Hawaii International Conference on System Sciences (pp. 1-9). IEEE.

PT XYZ. (2015a). Evaluasi Semester 1 dan Rencana Semester 2 Divisi IT Service Development 2015. Jakarta: PT XYZ.

PT XYZ. (2015). Laporan Bulan September Direktorat Datacom \& IT Services. Divisi IT Services.

PT XYZ. (2015b). Laporan Pipeline Layanan Cloud dari Aplikasi Salesforce. PT $\mathrm{XYZ}$

PT XYZ. (2014b). Laporan Produksi Desember 2014. Divisi Marketing
PT XYZ. (2014a). LAP-V1-PDM-006. Prosedur Product Development \& Management VAS . PT XYZ.

PT XYZ. (2015f). PT XYZ IT Services Needs Survey: Final Report. Jakarta: PT $\mathrm{XYZ}$

PT XYZ. (2014, Desember). Rencana Kerja dan Anggaran 2015. PT XYZ.

Rimal, B. P., Jukan, A., Katsaros, D., \& Goeleven, Y. (2010, December). Architectural Requirements for Cloud Computing Systems: An Enterprise Cloud Approach. Springer Science+Business Media B.V. , 3-26

Sekaran, U., \& Bougie, R. (2013). Research Methods for Business. Wes Sussex: John Wiley \& Sons, Ltd.

Tan, W.-G., Cater-Steel, A., \& Toleman, M. (2009). Implementing IT Service Management: A Case Study Focussing on Critical Success Factor. Journal of Computer Information Systems , 1-12.

Vouk, M. A. (2008). Cloud Computing Issues, Research and Implementation. Journal of Computing and Information Technology , 235-246.

Youssef, A. E. (2012). Exploring Cloud Computing Services and Applications. Journal of Emerging Trends in Computing and Information Sciences Vol. 3 No. 6 , 838847

Zhang, L.-J., \& Zhou, Q. (2009). CCOA: Cloud Computing Open Architecture. IEEE International Conference on Web Services (pp. 607-616). IEEE. 